\title{
Discussion on the Construction of College Smart Campus under the Background of Mobile Internet
}

\author{
Min Xiaocui, Li Peng, Wu Chumin \\ Guangzhou Huali Science and Technology Vocational College, Guangzhou Guangdong, 511325, \\ China
}

Keywords: mobile Internet, colleges and universities, smart campus, construction

\begin{abstract}
With the rapid development of Internet technology, people's lives and working methods are also quietly changing. The application of computer and Internet technology in people's daily life is increasingly widespread. In recent years, China's colleges and universities have begun to attach importance to building smart campuses, and applying Internet technology to the construction of smart campuses can effectively improve the degree of informationization in universities and improve teaching efficiency and effectiveness. This paper expounds the characteristics of colleges and universities' smart campuses, analyzes the key technologies in the intelligent campus information construction of colleges and universities, studies the smart campus volume structure and sub-module function design, and explores the application and implementation of mobile Internet in smart campus.
\end{abstract}

\section{Introduction}

With the rapid development of China's economy and science and technology, China's colleges and universities have begun to build digital campuses, and the level of informationization in universities is constantly improving. With the application and development of technologies such as Internet of Things, IntelliSense, Cloud Computing, and Mobile Internet, the construction of digital campus in colleges and universities needs to face challenges in mass storage, shared cloud, and big data analysis. At the same time, the development and application of these new technologies have also brought certain opportunities to the construction of digital campuses in universities, which can help universities build smart campuses. How to apply these technologies to the construction of smart campuses, improve user experience, optimize teaching methods, and improve teaching efficiency and effectiveness are issues that universities need to study depth.

\section{University Smart Campus Features}

In short, the smart campus is a comprehensive use of IoT technology, cloud computing technology, mobile Internet technology and other information foundations to form an intelligent campus environment, to build a comfortable, safe and convenient life, work and learning environment for college teachers and students. Smart campus can effectively improve teaching efficiency and effectiveness, and improve the efficiency of college work. In short, college smart campus has the 
following advantages: First, the Internet is widely used. At this stage, China has entered the information age. Network technology and information technology have been widely used in teaching. The smart campus mainly uses two kinds of network technologies, mobile internet and Internet of Things, to link various information in colleges and universities. College teachers and students can obtain relevant information anytime and anywhere through the network; second, teamwork is more convenient. With the rapid development of technology and economy, smart terminal devices have been popularized. At present, most teachers and students in colleges and universities use smart terminals to obtain the information they need. Therefore, universities can use smart technology to enhance the interaction between people and things. Most of the work needs to be completed by multiple cooperations, and the individual's sense of cooperation will directly affect the cooperation effect and work completion effect. Through the Smart Technology Division, the communication between teachers and students will be strengthened, and the sense of cooperation will be enhanced to facilitate teamwork. Third, business applications are intelligently integrated. At present, smart campuses are widely used in colleges and universities, and universities can realize the storage and use of data information through an open and integrated information architecture. Through personalized design, we can provide personalized services for college teachers and students, so as to give full play to the active role of smart campus colleagues, improve teaching efficiency and management efficiency. In order to promote the stable and sustainable development of colleges and universities, colleges and universities need to strengthen communication and cooperation with the outside world. For example, the transformation of teachers' academic activities into scientific and technological achievements can promote the development of science and technology in China while stimulating the enthusiasm of teachers. In addition, colleges and universities can strengthen academic exchanges with other institutions to grasp the social development trend and the development needs of colleges and universities, and continuously improve the development strategy in response to these problems, and promote the stable development of colleges and universities.

\section{Analysis of Key Technologies in the Construction of Intelligent Campus Information in Colleges and Universities}

\subsection{Cloud Computing Technology}

Cloud computing technology needs to be realized by using Internet technology. In short, this technology uses advanced technology to distribute computing in a distributed computer, thereby achieving the purpose of quickly calculating massive amounts of data information. Users only need to use Internet technology to obtain various data information calculated by the cloud computing platform. In order to build a smart campus, colleges and universities need to use cloud computing technology scientifically, use their personalized functions, and integrate cloud storage, cloud security and other technologies to build a smart campus service platform. In order to realize the goal of building a smart campus, colleges and universities cannot only use cloud computing technology. The main reason is that smart campuses involve a wide range of complexities. Therefore, universities need to use cloud computing technology, big data technology, mobile internet technology and other technologies to build development. And integrated information architecture to improve the level of information technology in colleges and universities.

\subsection{Big Data Technology}

With the rapid development of technology, the amount of data information is increasing sharply, while traditional database software cannot comprehensively collect, manage, and process related data information, but big data technology can quickly obtain effective information in massive data 
information, which can effectively improve data. Processing efficiency and effectiveness, so colleges and universities need to make full use of big data technology when building smart campuses. Smart campus is to use intelligent terminal equipment, sensible devices, information system mobile phones, analyze a large amount of data information, and understand various data and information of colleges and universities. In order to give full play to the positive role of the smart campus, it is necessary to use big data technology to quickly find valuable information in a large amount of data, and then correctly guide the university to carry out teaching management work, and promote the sustained and stable development of colleges and universities.

\subsection{Business Intelligence Technology}

Because business intelligence technology can help companies make the right decisions, business intelligence technology has been widely used in the business field. The use of business intelligence technology can transform various data information into corresponding knowledge, expand people's knowledge range, improve people's knowledge level, and help the leadership to make correct decisions. When colleges and universities are building smart campuses, they need to make full use of business intelligence technology. In short, when building a smart campus, colleges and universities need to make full use of data warehousing technology, online analytical processing technology, and data mining technology in business intelligence technology, and use these technologies to store and manage user data information systems, so as to scientifically analyze and organize user data information, and based on its analysis results to form corresponding report information, to provide an accurate basis for university management.

\subsection{Internet of Things Technology}

Internet of Things technology is developed by Internet technology. Internet of Things technology contains various applications in the Internet. Various resources on the Internet can also be obtained in the Internet of Things, thus forming a connection between various transactions. The goal of remote management of the network. It is precisely because of the above advantages of Internet of Things technology, colleges and universities need to make full use of Internet of Things technology when building smart campuses, use IoT technology to connect various affairs in colleges and universities; at the same time, we can use IoT technology to strengthen information communication and exchange, and strengthen University management work identification, supervision, etc., thereby improving the efficiency of college work.

\subsection{Mobile Internet Technology}

The integration of mobile communication technology and Internet technology is mobile internet technology, and universities need to actively use mobile internet technology when building smart campuses. Mobile internet technology can be used to build a mobile internet in colleges and universities, thus creating a mobile and intelligent environment for college teachers and students. Under this background, colleges and universities can build an intelligent platform to build an intelligent and stable network platform, and provide services for network learning, teaching and research, teacher-student exchanges and other activities of college teachers and students, and improve the level of intelligence and information in colleges and universities.

\subsection{Information Active Push Technology}

In addition to the above points, colleges and universities need to make full use of information to 
actively push technology when building smart campuses. In order to realize the information push function, it is necessary to keep in touch with the user by means of regular polling, SMS notification, etc., and in order to ensure the effectiveness of the push information, it is also necessary to make full use of data mining technology and information customization technology. Users can find relevant information according to their own needs, and push this information to college teachers and students. It can be seen that in the construction of smart campuses, in order to ensure the accuracy and relevance of information push, colleges and universities need to use information to actively push technology.

\section{Smart Campus Volume Architecture and Sub-Module Functional Design}

When building a smart campus, colleges and universities need to change the service concept, management business and information sharing system, reform the management process of colleges and universities, and improve the efficiency of colleges and universities. By studying the planning and construction mode of smart campus in many universities in China, the author tried to design the overall architecture model of smart campus construction. This model can provide data resources, messages, and identity functions for college teachers and students. First, the user can use the third-party authentication method for identity authentication; secondly, the user service hall with one-stop service function; again, the service bus and data; finally, the network integration, which also incorporates information standards and specifications. The system applies the data structure of the system, and clarifies the process of information collection, processing, processing, etc., which plays an important role in improving the degree of informationization in colleges and universities.

\begin{tabular}{|c|}
\hline Unified identity \\
\hline $\begin{array}{l}\text { Online service hall } \\
\text { (PC Portal |Mobile Portal |System Management |Application Management |Operation Data }\end{array}$ \\
\hline Service bus \\
\hline
\end{tabular}

$\uparrow$ Registration $\uparrow$ Competence service (API) $\uparrow$ Business (API) $\uparrow$ Data (API)

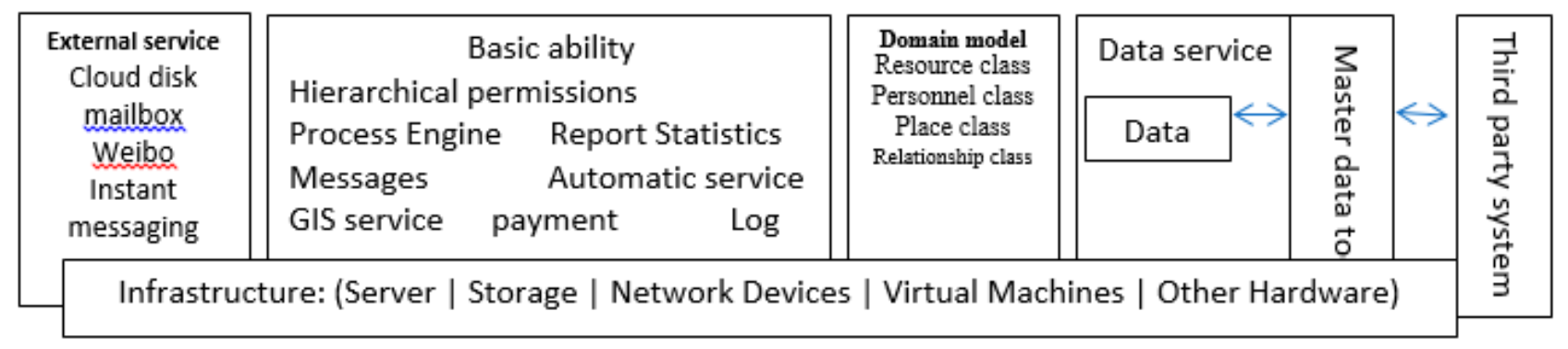

Figure 1 Overall Architecture Model of Smart Campus Construction

According to the smart campus architecture described above, the entire information system can be constructed by using the cloud architecture method, and the cloud infrastructure technology is used to virtualize the infrastructure resources of the base layer to provide corresponding resources for the underlying hardware system. In order to ensure the security of the system, the private cloud is used to provide data storage service for the smart campus service platform. It is set in the campus intranet and has an external access interface. In order to improve the level of informationization in colleges and universities, it is necessary to use a combination of cloud computing technology, big data technology, business intelligence technology, mobile internet technology and other new technologies to build a smart campus, and to open up, intelligent work, study and living environment for university teachers 
and students. College teaching efficiency and work efficiency, improve the humanization level of university management.

\section{The Use and Implementation of Mobile Internet in Smart Campus}

\subsection{Strengthening Theoretical Knowledge Research}

In order to ensure that colleges and universities can successfully complete the construction of smart campus, it is necessary to thoroughly study relevant theories and make full use of advanced information technology to improve the teaching management level of colleges and universities and improve the efficiency and efficiency of college teaching. When studying relevant theories, researchers should pay attention to the following points: First, it is necessary to strengthen the research on the design and construction theory of smart campus; secondly, it is necessary to strengthen the theoretical research on the construction of smart campus; finally, it is necessary to strengthen the construction of mobile Internet applied research in the construction of smart campus. Through in-depth study of relevant theories, colleges and universities can provide theoretical support for the construction of smart campuses, and thus ensure the smooth construction of smart campus construction.

\subsection{Develop a Smart Campus Service Platform Construction Plan}

The smart campus service platform has a wide range of aspects, and it needs to have multiple functions, such as news information, campus services, and message push. When building a smart campus service platform, colleges and universities need to rely on servers, web portals, IOS and other servers. At the same time, smart campus service platforms need to set service structures according to user needs, and ensure that these interfaces match information technology. When constructing a smart campus service platform, colleges and universities need to scientifically select the appropriate server. At the same time, they must pay attention to the service platform design work and actively introduce advanced information technology to ensure the quality of the smart campus service platform construction. The mobile terminal is an important device for connecting the mobile campus server and the user terminal, and can realize transmission of various data of the server terminal and the user terminal. When building a smart campus service platform, it is necessary to pay attention to the quality of the user-side setting, and it is necessary to set different terminal interfaces for college teachers and students. For college students, they need to be set as ordinary terminals, which mainly include modules such as student personal information management, information management, achievement inquiry, teacher-student exchange, etc. The student department chooses different functions according to their own needs; for college teachers, this is required for management terminals. It mainly includes modules for campus information release, information push management, achievement information management, teacher-student exchange, etc. Only teachers with relevant authority can use this terminal.

\subsection{Building a Smart Campus Service Platform Consulting Service Module}

When building a smart campus, it is also necessary to use the mobile Internet technology to build a smart campus service platform consulting service module. After building this module, users can quickly find all kinds of information they need through the smart campus service platform. At the same time, they can also set up mobile terminal columns and provide user comment management services for users. Users can find the required information through the smart campus service platform consulting service module, which can effectively improve information utilization and management 
efficiency. When constructing the consulting service module of the smart campus service platform, the technical personnel need to set the collection column according to the content of the column reasonably. In this process, the intelligent crawler foot technology is needed. After the completion of the writing, it is necessary to intelligently filter and write the content for the relevant website information, and utilize the content. The information extraction algorithm cleans up the unwanted information, thereby achieving the goal of automatically collecting the body content. In summary, a number of advanced technologies are required to build a smart campus service platform consulting service module.

\section{Conclusion}

To sum up, in order to improve the level of informationization in colleges and universities and promote the development of colleges and universities in the direction of modernization and intelligence, universities need to strengthen the construction of smart campuses. When building a smart campus, colleges and universities need to focus on the students' learning and build a platform that can provide students with corresponding services. Strengthening the construction of smart campuses in colleges and universities in the context of mobile internet can effectively improve the efficiency of colleges and universities, enhance the teaching effect, and promote the stable development of colleges and universities.

\section{Acknowledgements}

Support project of Guangdong province university student science and technology innovation cultivation project (pdjh2018b0976); Institute of quality engineering- 《Web design and production》 quality online open course(HLZ011801)

\section{References}

[1] Guozhen Du. Discussion on the Construction of University Smart Campus under the Background of Big Data [J]. China New Communications, 2016(24): 25-25.

[2] Lixiang Wang. Thoughts and Discussion on the Construction of Smart Campus in Colleges and Universities [J]. China New Communications, 2016, 18(24): 116-116.

[3] Shenghua Wang. Analysis and Discussion on the Construction of University's Smart Campus under the Big Data Environment [J]. Computer Knowledge and Technology, 2016, 12(19): 218-220.

[4] Rao Fan. Research on the Construction of University Education Informationization Based on Smart Campus under the Environment of Internet + Education [J]. Jiangsu Science and Technology Information, 2017(29):78-80.

[5] Lei Zhang. Discussion on the Application of University Smart Campus Construction in Big Data Environment [J]. Intelligent Architecture and Smart City, 2017(9): 42-43.

[6] Lei Zou. Discussion on the Construction of University Smart Campus Platform under the Background of "Internet +"[J]. Academic Journal, 2018(1): 8-9. 